\title{
Fragilidades da educação ambiental na escola pública: a formação dos professores
}

\author{
Weaknesses of environmental education in public schools: \\ the teacher training
}

\author{
Aldineia BUSS ${ }^{1}$ \\ Mariela Mattos da SILVA²
}

\begin{abstract}
Resumo
Neste trabalho, buscou-se compreender sobre as condições requeridas para o desenvolvimento da Educação Ambiental Crítica nas escolas, de forma especial, a capacitação docente. A pesquisa foi realizada com a participação de 34 professores de duas escolas públicas estaduais em Colatina-ES. Os dados foram coletados a partir de questionários e a análise feita de forma qualitativa e quantitativa. Os resultados evidenciaram que há deficiência na formação dos professores quanto às questóes ambientais, tanto na formação inicial quanto na continuada. Havendo, portanto, a necessidade do aprimoramento e da oportunizaçáo da formação docente condizente com os objetivos da Educação Ambiental Crítica.
\end{abstract}

Palavras-chave: Educação ambiental crítica. Formação de professores. Escola pública. Educação básica.

\begin{abstract}
In this work, we try to understand the conditions required for the development of Critical Environmental Education in schools, in a special way, the teacher training. The research was conducted with the participation of 34 teachers from two state public schools in Colatina-ES. Data were collected from questionnaires and qualitative and quantitative analysis was performed. The results showed that there is a deficiency in teacher training regarding environmental issues, both in initial and continued training. Therefore, there is a need for the improvement and opportunization of teacher education consistent with the objectives of Critical Environmental Education.
\end{abstract}

Keywords: Critical environmental education. Teacher training. Public school. Basic education.

1 Mestre em biologia vegetal pela Universidade Federal de Uberlândia (UFU). Doutoranda no programa de Pós-graduação em Biologia Vegetal (PPGBV) da Universidade Federal de Minas Gerais (UFMG). E-mail: buss.aldineia@gmail.com. Lattes: http://lattes.cnpq.br/3419126367059552. Orcid: https:// orcid.org/0000-0003-0121-1080.

2 Doutora em Fisiologia Vegetal pela Universidade Federal de Viçosa (UFV). Programa de Pós-Graduação em Biologia Vegetal (PPGBV) da Universidade Federal do Espírito Santo (UFES). E-mail: marielamtts@ gmail.com. Lattes: http://lattes.cnpq.br/8607472152014786. Orcid: https://orcid.org/0000-00018040-1688. 


\section{Introdução}

O modo predominante como a sociedade se organiza e explora os recursos naturais, tem causado prejuízos cada vez mais significativos para o meio ambiente que inclui o espaço e os que nele habitam. No entanto, a preocupaçáo com as possíveis consequências só ganhou espaço para discussóes na segunda metade do século $\mathrm{XX}$, quando desastres socioambientais se tornaram alarmantes. Da mesma forma, a Educaçáo Ambiental (EA) também veio a existir em um momento tardio (CZAPSKI, 1998). O termo "educação ambiental" aparece pela primeira vez em 1965, na Conferência de Educação da Universidade de Keele, da Inglaterra. No Brasil, a EA chega na década de 1970, muito embora já fosse praticada na década de 1950 por alguns professores e naturalistas. O país recebeu influência da Conferência das Naçóes Unidas sobre Meio Ambiente e Desenvolvimento, a qual sediou no Rio de Janeiro em 1992, a ECO-92 (CZAPSKI, 1998), e pouco depois institui formalmente a EA através da publicação da Lei No 9.795/99.

A Constituição da República Federativa do Brasil de 1988 já incumbia ao poder público promover a EA em todos os níveis de ensino (BRASIL, 1988), mas é a Lei No 9.795/99 que institui a Política Nacional de Educação Ambiental, define a EA como componente da educaçấo nacional em todos os níveis e modalidades do processo educativo e elenca no Art. $5^{\circ}$ os seus objetivos. Dentre eles:

Art. 5o. [...] III - o estímulo e o fortalecimento de uma consciência crítica sobre a problemática ambiental e social; IV - o incentivo à participação individual e coletiva, permanente e responsável, na preservaçáo do equilíbrio do meio ambiente, entendendo-se a defesa da qualidade ambiental como um valor inseparável do exercício da cidadania [...]. (BRASIL, 1999)

Destacando-se que a EA surgiu com o principal objetivo de formar indivíduos capazes de ter uma interpretação e atuação crítica no que envolve as questóes ambientais. Para isso, os documentos também recomendam que a EA ocorra em uma perspectiva holística e interdisciplinar no contexto social e histórico em que vivem as comunidades, como destaca o Tratado de Educação Ambiental para Sociedades Sustentáveis e Responsabilidade Global (FORUM INTERNACIONAL DAS ONGs, 1992).

Nessa perspectiva, o educador ambiental pode inspirar-se em Freire (2013), que não trata especialmente da $\mathrm{EA}$, mas questiona o porquê de não se aproveitar as experiências dos alunos e relacioná-las aos conteúdos ensinados na escola, inclusive as experiências da convivência com problemas ambientais. Para o autor, 
muito mais importante do que adaptar-se a realidade, é o tornar-se capaz de intervir nela. E isso para ele é um ato ideológico e político. Quando aborda o saber teórico-prático da realidade necessário ao professor, colocando-se na condição de docente, afirma: "Preciso, agora, saber ou abrir-me à realidade desses alunos com quem partilho a minha atividade pedagógica. Preciso tornar-me, se não absolutamente íntimo de sua forma de estar sendo, no mínimo, menos estranho e distante dela" (FREIRE, 2013, p.87).

Para além de uma EA que proporcione um olhar sobre a realidade local dos alunos, uma Educação Ambiental Crítica é necessária para a promoção da emancipação dos sujeitos e da transformação social no que visa um ambiente mais justo e igualitário. A EA Crítica surge da pedagogia crítica, "processo educativo dialógico que problematiza as relaçóes sociais de exploração e dominação”, portanto visa proporcionar a compreensão da realidade, das relaçóes sociais no passado, no presente e nas suas implicações para o futuro, no sentido da educação libertadora de Paulo Freire, para que a transformação social seja possível (LOUREIRO; TREIN; TOZONI-REIS; NOVICKI, 2009, p. 87).

Após anos dos primeiros avanços da EA em termos de legislação, diversos estudos têm mostrado que há dificuldades na sua implantação prática nas escolas (AMARAL; CARNIATTO, 2011; SEPULCRI; TRISTÃO, 2017; TORALES, 2013; TRAJBER; MENDONÇA, 2007). Guimarães (2004), ao defender ações pedagógicas no âmbito da EA Crítica, afirma que, de certa forma, isso já vem sendo difundido no contexto escolar a partir da proposta de projetos pedagógicos, nos quais o tema meio ambiente tem o maior destaque, entretanto, na maioria das vezes, esses projetos reproduzem práticas voltadas apenas para a mudança comportamental do indivíduo, sem relacionar suas atividades à realidade socioambiental em que as escolas estáo inseridas.

Dantas (2011) destaca que muitas vezes a EA é desenvolvida de forma tradicional e conservadora, considerando o meio natural de forma isolada, importando-se apenas com as consequências da degradação ambiental e não com as suas causas, ignorando a complexidade dos problemas socioambientais, o que acaba por transferir a responsabilidade pela degradação ambiental para o indivíduo, sem, contudo, criticar o modelo organizacional de sociedade. Nesse sentido, Loureiro (2013) adverte que essa linha histórica de argumentaçáo que homogeneíza o humano como uma espécie responsável pela intensa exploração e degradação da natureza, não permite compreender as causas dos problemas ambientais a fundo, ao deixar de atribuir responsabilidades peculiares a classes, grupos, governos e países que interferem de modo desproporcional no processo de uso da natureza.

Além disso, segundo Vieiras e Tristão (2016), frequentemente, a EA é trabalhada a partir de um enfoque maior em problemas futuros do que nos atuais, 
como se as consequências da degradação ambiental ainda estivessem longe de interferir no contexto vivido. No entanto, tais problemas estão presentes e de forma cada vez mais expressiva, sendo urgente a sua devida reflexão no cotidiano escolar. Diante disso, requerer-se aí uma EA que se comprometa a tratar os problemas ambientais de forma contextualizada e inter-relacionados no tempo e no espaço, com políticas de formação a partir das experiências vivenciadas pelos sujeitos em seu cotidiano.

Assim, além de continuar os estudos sobre como a EA vem sendo desenvolvida nas escolas, é importante identificar as dificuldades e propor alternativas para que a EA ocorra da forma como foi pensada e descrita nos documentos de sua implantação. O presente trabalho resulta de uma monografia cujos resultados preliminares em Buss e Silva (2017) demonstraram que poucas atividades de EA foram desenvolvidas no contexto do desastre de Mariana - MG nas escolas estaduais do município de Colatina - ES, cuja população, em grande parte, vivenciou diretamente as consequências da tragédia. Além disso, os autores mostraram que muitos professores reconhecem que a EA desenvolvida na escola em que atuam é insuficiente, e apontam como causas que dificultam esse processo: "pouca participaçáo dos alunos, a falta de envolvimento dos profissionais, poucos resultados quando se trabalha, restrita às disciplinas de Biologia e Geografia, falta de tempo da equipe pedagógica e a falta de ferramentais didáticas e de profissionais qualificados" (BUSS; SILVA, 2017, p. 1070). Assim, no presente estudo, buscou-se compreender sobre as condiçóes requeridas para o desenvolvimento da EA crítica nas escolas, de forma especial, a capacitação docente.

\section{Metodologia}

A pesquisa foi realizada nos turnos matutino e vespertino das escolas EEEFM Rubens Rangel (Escola I) e EEEFM Conde de Linhares (Escola II), situadas na sede do Município de Colatina - ES. Na Escola I, dos 21 docentes atuantes nos turnos pesquisados, 13 (62\%) participaram da pesquisa, enquanto na Escola II, do total de 41 professores, 11 (27\%) participaram.

A coleta de dados foi realizada através de questionário com questóes abertas e fechadas, em visitas às escolas durante o segundo semestre de 2016. A pesquisa foi realizada após os devidos esclarecimentos e o consentimento dos participantes, o que foi formalizado no Termo de Consentimento Livre e Esclarecido. A análise de dados foi realizada de maneira qualitativa conforme Bardin (1977), tendo sido as respostas agrupadas em categorias para posterior tabulação, e quantitativa em percentuais utilizando o software Microsoft Excel. 


\section{Resultados e Discussão}

Os professores participantes da pesquisa têm faixa etária entre 28 e 57 anos. Dos 13 participantes na Escola I, quatro são do sexo masculino e nove do feminino. Na Escola II, do total de 11 participantes, cinco são do sexo masculino e seis do feminino. Oito docentes na Escola I e cinco na Escola II têm pósgraduação e a maioria atua a mais de quatro anos na comunidade pesquisada, sendo nove na Escola I e oito na Escola II.

$\mathrm{Na}$ busca de verificar se há e quais são as dificuldades encontradas pelos professores para o desenvolvimento da EA, buscou-se responder questóes pertinentes ao apoio da escola e da comunidade nas açóes relacionadas a EA, as causas que dificultam o seu desenvolvimento, bem como sobre a formação docente.

Sobre as primeiras questóes em análise, a maioria dor professores, em ambas as escolas, afirmou que a escola na qual trabalham oferece apoio e infraestrutura adequados para o desenvolvimento das atividades de EA (77\% e 91\%, nas Escolas I e II, respectivamente) e a maioria dos docentes na Escola I disseram se sentir apoiados pelas famílias (77\%), na Escola II, por sua vez, esse percentual é menor (45\%) (Tabela 1).

Tabela 1: Percepção dos professores quanto ao apoio recebido para o desenvolvimento da EA nas escolas pesquisadas.

\begin{tabular}{l|c|c|c|c}
\hline Questionamentos & Escola & Sim & Não & Não respondeu \\
\hline $\begin{array}{l}\text { A escola oferece apoio/ } \\
\text { infraestrutura para o } \\
\text { desenvolvimento de atividades } \\
\text { relacionadas à EA? }\end{array}$ & Escola I & $77 \%$ & $15 \%$ & $8 \%$ \\
\cline { 2 - 5 } & Escola II & $91 \%$ & - & $9 \%$ \\
\hline $\begin{array}{l}\text { Você se sente apoiado(a) pelas } \\
\text { famílias dos alunos para o } \\
\text { desenvolvimento de atividades } \\
\text { relacionadas à EA? }\end{array}$ & Escola I & $77 \%$ & $8 \%$ & $15 \%$ \\
\cline { 2 - 5 }
\end{tabular}

Fonte: Do autor.

Ao questionar os professores sobre as causas que podem dificultar o desenvolvimento da EA, obteve-se que para a maioria dos professores (69\%) da Escola I, a causa que mais dificulta é a falta de tempo para planejamento, enquanto para os professores da Escola II, falta de tempo para planejamento (27\%), falta de recursos humanos qualificados $(27 \%)$ e precariedade de recursos materiais $(27 \%)$ são as principais causas (Tabela 2). 
Tabela 2: Principais dificuldades que impediram ou dificultaram o trabalho com EA.

\begin{tabular}{l|c|c}
\hline Principais dificuldades citadas & Escola I & Escola II \\
\hline Falta de tempo para planejamento & $69 \%$ & $27 \%$ \\
\hline Conflito de interesses & $23 \%$ & $18 \%$ \\
\hline $\begin{array}{l}\text { Dificuldade da comunidade escolar para } \\
\text { entender as questões ambientais }\end{array}$ & $23 \%$ & $9 \%$ \\
\hline Falta de recursos humanos qualificados & $15 \%$ & $27 \%$ \\
\hline $\begin{array}{l}\text { Falta de integração entre professores e } \\
\text { direção }\end{array}$ & $8 \%$ & - \\
\hline Precariedade de recursos materiais & $8 \%$ & $27 \%$ \\
\hline Não respondeu & $8 \%$ & $27 \%$ \\
\hline
\end{tabular}

Fonte: Do autor.

Falta de recursos humanos qualificados, falta de recursos materiais e a falta de tempo para o planejamento, tem sido relatado como os principais fatores que dificultam o desenvolvimento de atividades de EA nas escolas (AMARAL; CARNIATTO, 2011; LAMOSA; LOUREIRO, 2011; TRAJBER; MENDONÇA, 2007; VIEIRAS; TRISTÃO, 2016), ficando clara a necessidade de políticas que invistam nesses pontos.

Em se tratando da formação docente, quanto a atualização dos professores em assuntos relacionados à EA, 62\% e 73\% (das Escolas I e II, respectivamente) afirmam que se informam sobre os problemas ambientais ocorridos na comunidade em que a escola está inserida, enquanto $38 \%$ e $18 \%$ dos professores (das Escolas I e II, respectivamente) responderam que se informam com frequência sobre esses mesmos problemas (Figura 1A). Já quando se trata da dedicaçáo à EA no planejamento coletivo, tanto na Escola I quanto na II, a maioria dos professores (69\% e 73\%, respectivamente) afirma que somente "às vezes" a EA é tema de estudo no planejamento pedagógico coletivo (Figura 1B). 


\section{Figura 1: Atualização de professores quanto à temática da EA nas escolas pesquisadas}
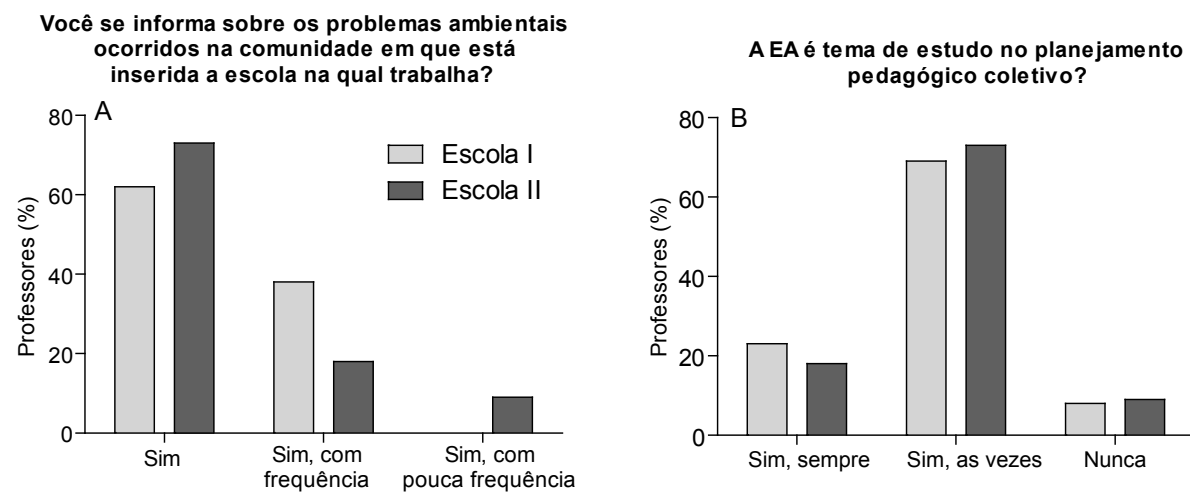

Os professores afirmaram ter a prática de se atualizar quanto aos problemas ambientais da comunidade na qual atuam, todavia, é preocupante que a EA náo seja tratada com frequência no planejamento pedagógico coletivo, uma vez que esse planejamento entre professores de diferentes disciplinas é essencial para que as atividades de EA sejam desenvolvidas de forma interdisciplinar (LOUREIRO, 2004).

Talvez a pouca inclusão dos temas pertinentes a EA no planejamento pedagógico coletivo, seja reflexo da deficiência na formação dos professores para a EA, já que, apenas 23\% dos docentes na Escola I e nenhum na Escola II tiveram alguma formação em EA na graduação (Figura 2A). Somados a isso, somente 15\% dos docentes na Escola I e 36\% na Escola II participou de alguma formação em EA nos últimos anos (Figura 2B), e em ambas as escolas a maioria dos professores ( $54 \%$ e $55 \%$, nas escolas I e II, respectivamente) considera a sua formação regular, sendo apenas 8\% na Escola I que considera sua formação em EA ótima e 15\% e 9\% (Escola I e II, respectivamente) julga sua formação em EA excelente (Figura 2C).

\section{Figura 2: Formação dos professores relacionada a Educação Ambiental}
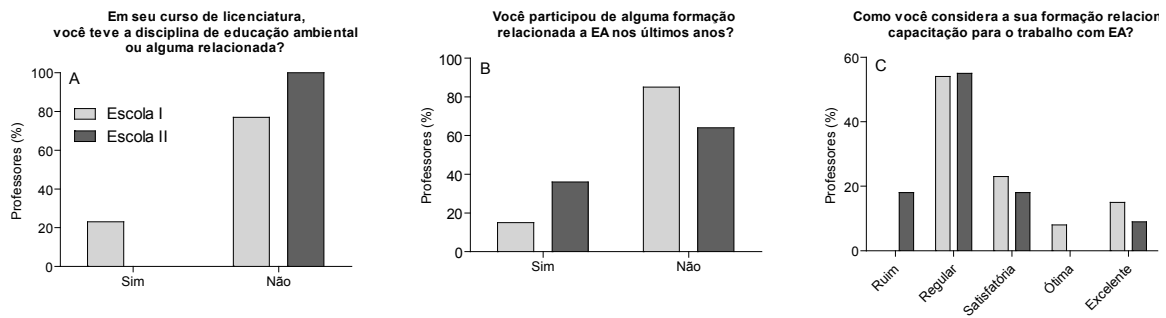
Estes resultados corroboram com inúmeros outros trabalhos. Figueiredo (2014), ao pesquisar a formação inicial e continuada de professores do Ensino Fundamental I e II das escolas municipais e estaduais de Cravinhos-SP, identificou que a formação inicial da maioria dos docentes é insuficiente para o trabalho consistente com a EA. Ferrazza e Nishijima (2016), em uma pesquisa realizada em uma escola estadual de Catuípe-RS, constataram que 60\% dos professores participantes da pesquisa não teve qualquer formação em EA durante sua graduaçáo. Viana e Oliveira (2006), verificaram que somente $20 \%$ dos professores de uma escola municipal de Ensino Fundamental, em Itapetinga-BA, havia tido alguma formação para trabalhar com EA na escola. Ferreira, Tessmann e Tessmann (2016), encontraram que apenas $23,7 \%$ dos professores das escolas públicas realizaram algum curso de capacitação na área ambiental. Vieiras e Tristâo (2016), a partir de entrevistas realizadas com professores de duas escolas do município de Colatina-ES, observaram que no processo de formação inicial dos professores os espaços ocupados pela educaçáo ambiental não ocorrem, ou pelo menos não são percebidos em algumas disciplinas, como por exemplo, na formação do professor de matemática.

Um agravante desse problema é que há pouco investimento por parte do sistema educacional em qualificar os docentes para o trabalho com EA no ensino formal (VIANA; OLIVEIRA, 2006). No entanto, a Política Nacional de Educação Ambiental prevê a formação complementar para os professores em exercício (BRASIL, 1999). Loureiro e Cossío (2007), afirmam que para que a EA desenvolvida nas escolas seja aprimorada, são necessária políticas públicas que dediquem especial atenção ao processo de formação de educadores ambientais, tanto na formação inicial quanto na formação continuada.

Quando se trata da formação inicial, da graduação, conforme levantamento de dados oficiais e da literatura relacionada, Souza (2016) concluiu que as universidades brasileiras oferecem poucas vagas em cursos voltados para a área ambiental. Além disso, a distribuição desses cursos é desigual entre as regiōes do país, e consequentemente a produçáo acadêmica e a participação de docentes e discentes das instituiçóes de ensino superior em eventos que tratam da temática ambiental, também são desiguais. Para a autora, a contribuição da universidade pública na formaçáo relacionada às questôes ambientais, é insuficiente. Agudo e Tozoni-Reis (2018), afirmam que a formação inicial dos professores atuantes na escola pública é realizada principalmente em instituiçóes de ensino superior privadas, organizaçóes comerciais que estão mais interessadas no lucro.

No contexto do ensino superior em geral, Mota e Kitzmann (2017) observaram que a integralizaçáo das questóes ambientais no currículo dos cursos superiores é modesta, apontando a inflexibilidade e organização dos currículos como dificuldades a serem superadas. Dickmann e Henrique (2017), ao analisar 
os cursos de licenciatura na Universidade Comunitária da Regiāo de Chapecó (Unochapecó), observaram que a presença da temática ambiental no currículo destaca-se apenas no curso de Ciências Biológicas, aparecendo de forma esporádica e acrítica nos demais cursos.

Via de regra, a EA nos cursos superiores é desenvolvida em disciplinas específicas (SILVA; PEREIRA, 2015), o que não pode alcançar plenamente a formação emancipatória, pois, conforme Tristáo (2004, p. 24), a lógica cartesiana, que fragmenta o objeto de conhecimento, não atende aos objetivos da EA crítica que requer uma visão holística, onde não há fronteira "entre mundo natural e social, entre cultura e natureza, entre sujeito e objeto". Morin (2013, p. 40) é enfático ao afirmar que "A fronteira disciplinar, com sua linguagem e com os conceitos que lhe são próprios, isola a disciplina em relação às outras e em relação aos problemas que ultrapassam as disciplinas". Em outras palavras, Guimarães (2004) salienta que a fragmentação e a simplificação reduzem a compreensão da realidade, o que não contribui para a compreensão da relação complexa da sociedade com o ambiente. Desse modo, é necessário que a formação dos professores em EA ocorra em uma perspectiva interdisciplinar.

Ainda em se tratando do currículo nos cursos superiores, conforme Souza (2016), há que se preocupar com a apropriação do currículo pelos interesses do mercado. Segundo a autora, ao atender aos interesses do mercado, ao deixar que ele influencie na produção de conhecimentos, a universidade deixa de contribuir para a superaçáo dos problemas ambientais, já que nesse contexto, não cabem reflexóes sobre os problemas socioambientais em decorrência do modelo de organização social baseado na exploração e no acúmulo de capital. A autora afirma também, que a $\mathrm{EA}$ ainda não está completamente incluída no ensino superior e que o meio ambiente é um campo social em disputa por interesses de diversos grupos, podendo a compreensão sobre o meio ambiente assumir diferentes interpretaçóes. Dessa forma, as abordagens diferentes da EA podem atender a uma educaçáo libertadora ou opressora.

Freire, Figueiredo e Guimarães (2016), questionam ainda, a forma tradicional como se dá a formação ambiental no ensino superior, e afirmam que o momento é de transição paradigmática na busca de uma formação que proporcione a identidade crítica, emancipada e pesquisadora do professor e apresenta a formação dialógica como um caminho possível, na qual o educador ambiental em formação é o próprio autor de sua formação na relação com outros seres em espaços diversos, sendo fundamentais as relaçóes dialógicas horizontais, diante de um sistema hegemônico de sociedade, na busca por superar as relaçóes sociais de dominação e exploração.

Há diversos apontamentos na literatura no que visa superar as dificuldades relacionadas à formação docente e a interação entre as disciplinas. Por exemplo, 
Bigotto (2008) observou que muitos professores da educação básica sentem a necessidade de um especialista para orientar e coordenar as atividades de EA desenvolvidas, de forma interdisciplinar. Agudo e Tozoni-Reis (2018), Loureiro (2007), Freire, Figueiredo e Guimarães (2016), sugerem a pesquisa ação como forma de a universidade interagir com as escolas de educação básica, permitindo tanto a formação dos professores/pesquisadores, quanto dos professores em exercício, num diálogo permanente. Açôes nesse sentido são necessárias, já que, como afirmam Guimaráes (2004) e Batista e Silva (2015), para a maioria dos professores atuantes na escola pública, a discussão da inserção da dimensão ambiental no processo educacional não ocorreu durante a formação, nem na sociedade, por ser essa uma discussão ainda muito restrita.

Embora a introdução da EA nas universidades brasileiras tenha se dado há poucas décadas, em 1980 tem-se os primeiros registros de dissertaçóes de mestrado e em 1990 são abertos os primeiros cursos de pós-graduação na área (GUERRA; GUIMARÁES, 2007), as universidades devem exercer o seu papel social e político diante dos problemas socioambientais vigentes, incluindo-os no ensino, na pesquisa e na extensão, como prioridade do projeto institucional. Entretanto, há que se vencer a lógica da produçáo, uma vez que a EA crítica faz o caminho inverso ao postulado pelo capitalismo (BATISTA; SILVA, 2015), e romper com a lógica racionalista que resulta na falta de integração entre os saberes (TRISTÃO, 2004).

\section{Considerações Finais}

A insuficiência no desenvolvimento de uma educação ambiental crítica está em grande parte justificada na deficiência quanto à formação dos professores, tanto na formaçáo inicial, quanto na continuada, como revelam os dados desta pesquisa, corroborada por tantas outras. A insuficiência da universidade pública, o currículo historicamente fragmentado e resistente a mudanças, e a presença do interesse mercantil no currículo são fatores que dificultam a formação do professor emancipado, uma vez que a educação ambiental não é baseada na lógica cartesiana, mas na dialética.

Assim sendo, os desafios são profundos na busca de uma educação ambiental crítica nas escolas, mas sabe-se que o aprimoramento e a oportunização da formação docente condizente com os objetivos da EA crítica se fazem urgentes e necessários. Devendo essa formação ser dinâmica, num diálogo permanente entre as escolas de educação básica, a universidade e a sociedade que também é cada uma dessas instituições, estando aí compreendidas políticas públicas que sustentem essa formação. 


\section{Referências}

AGUDO, M. M.; TOZONI-REIS, M. F. C. A formação continuada de pedagogos em educação ambiental em duas escolas públicas do estado de São Paulo. Olhares \& Trilhas, Uberlândia, v. 20, n. 2, mai./ago. 2018. Disponível em: http://www. seer.ufu.br/index.php/olharesetrilhas/article/view/34018/25307. Acesso em: 29 ago. 2019.

AMARAL, A. Q.; CARNIATTO, I. Concepçóes sobre projetos de educaçáo ambiental na formação continuada de professores. Revista Electrónica de Investigación em Educación en Ciencias, v. 6, n. 1, p. 113-123, jul. 2011. Disponível em: https://dialnet.unirioja.es/servlet/articulo?codigo $=4460264$. Acesso em: 29 ago. 2019.

BARDIN, L. Análise de conteúdo. 70. ed. São Paulo: Persona. 1977.

BATISTA, M. S. S.; SILVA, R. P. Políticas e gestão da educação ambiental do ensino superior. In: BANDEIRA, H. M. M.; IBIAPINA, I. M. L. M.; CABRAL, M. B. L. (Org.). Pesquisa em Educação: Unidade na Diversidade. Fortaleza: Imprece, 2015. p. 45-52.

BIGOTTO, A. C. Educaçáo ambiental e o desenvolvimento de atividades de ensino na escola pública. 2008. 135 f. Dissertação (Mestrado em Educação). Faculdade de Educação da Universidade de São Paulo, São Paulo, 2008. Disponível em: http://www.teses.usp.br/teses/disponiveis/48/48134/tde12062008-152040/pt-br.php. Acesso em: 29 ago. 2019.

BUSS, A.; SILVA, M. M. A tragédia de Mariana e suas implicaçóes na educação ambiental escolar. In: SEABRA, G. (Org.). Educaçáo ambiental: ecopedagogia e sustentabilidade dos recursos naturais. Ituiutaba: Barlavento, 2017. p. 1061-1073. BRASIL. Constituição (1988). Constituição da República Federativa do Brasil. Diário Oficial da República Federativa do Brasil, Poder Executivo, Brasília, out. 1988.

BRASIL. Lei no 9.795 de 27 de abril de 1999. Dispóe sobre a educação ambiental, institui a Política Nacional de Educação Ambiental e dá outras providências. Coleçáo de Leis da República Federativa do Brasil, Brasília, abr. 1999. Disponível em: https://www2.camara.leg.br/atividade-legislativa/legislacao/ republica. Acesso em: 25 mai. 2016.

CZAPSKI, S. A implantaçáo da educaçáo ambiental no Brasil. Brasília: Coordenação de Educação Ambiental do Ministério da Educação e do Desporto, 1998. 
DANTAS, T. B. Desenvolvimento sustentável versus decrescimento: educaçáo ambiental, cidadania ambiental e o modelo técnico-pedagógico de agenda ambiental escolar da secretaria de educaçáo do município de Manaus. 2011. 201 f. Dissertação (Mestrado em Ciências Jurídicas). Universidade Federal da Paraíba, João Pessoa, 2011. Disponível em: https://repositorio.ufpb.br/jspui/ handle/tede/4354. Acesso em: 29 ago. 2019.

DICKMANN, I.; HENRIQUE, L. Formação inicial de educadores ambientais: desafios, limites e avanços. Revista de Educaçáo Pública, Cuiabá, v. 26, n. 63, p. 839-853, set./dez. 2017. Disponível em: http://www.periodicoscientificos.ufmt. br/ojs/index.php/educacaopublica/article/view/3722. Acesso em: 29 ago. 2019.

FERRAZZA, T.; NISHIJIMA, T. A educação ambiental na formação e atuação dos professores de um colégio estadual no município de Catuípe-RS. Revista Eletrônica de Mestrado em Educação Ambiental, v. 33, n.1, p. 281-298, jan./ abr. 2016. Disponível em: https://periodicos.furg.br/remea/article/view/5368. Acesso em: 29 ago. 2019.

FERREIRA, A. C. S.; TESSMANN, M. S.; TESSMANN, C. Educação Ambiental no Ensino Médio do município de Garanhuns (PE): saberes e práticas docentes. Revista Brasileira de Educaçáo Ambiental, São Paulo, v.11, n. 4, p. 210-225, 2016. Disponível em: https://periodicos.unifesp.br/index.php/revbea/ article/view/2106. Acesso em: 29 ago. 2019.

FIGUEIREDO, P. B. Formaçáo e atuaçáo de professores em educaçáo ambiental. 2014. 171 f. Dissertação (Mestrado em Educação para a Ciência). Universidade Estadual Paulista. Faculdade de Ciências, Bauru, 2014. Disponível em: https://repositorio.unesp.br/handle/11449/110900. Acesso em: 17 jul. 2020 .

FREIRE, L.; FIGUEIREDO, J.; GUIMARÁES, M. O papel dos professores/ educadores ambientais e seus espaços de formação. Qual é a educação ambiental que nos emancipa? Pesquisa em Educação Ambiental, v.11, n.2, p. 117-125, 2016. Disponível em: https://www.periodicos.rc.biblioteca.unesp.br/index.php/ pesquisa/article/view/11971. Acesso em: 29 ago. 2019.

FREIRE, P. Pedagogia da Autonomia: saberes necessários à prática educativa. 44. ed. Rio de Janeiro: Paz e Terra, 2013.

GUERRA, A. F. S.; GUIMARÁES, M. Educação Ambiental no Contexto Escolar: Questóes levantadas no GDP. Pesquisa em Educaçáo Ambiental, v. 2, n. 1, p. 155-166, 2007. Disponível em: https://www.periodicos. rc.biblioteca.unesp.br/index.php/pesquisa/article/view/6136. Acesso em: 29 ago. 2019. 
GUIMARÃES, M. Educação Ambiental Crítica. In: LAYRARGUES, P. P. (Org.). Identidades da educaçáo ambiental brasileira. Brasília: Ministério do Meio Ambiente. Diretoria de Educação Ambiental, 2004. p. 25-34.

GUIMARÁES, M. A formaçáo de educadores ambientais. 3. ed. Campinas, SP: Papirus, 2004.

LAMOSA, R. A. C.; LOUREIRO, C. F. B. A educação ambiental e as políticas educacionais: um estudo nas escolas públicas de Teresópolis (RJ). Educaçáo e Pesquisa, São Paulo, v. 37, n.2, p. 279-292, 2011. Disponível em: http://www. scielo.br/pdf/ep/v37n2/v37n2a05.pdf. Acesso em: 29 ago. 2019.

LOUREIRO, C. F. B. Educação ambiental transformadora. In: LAYRARGUES, P. P. (Org.). Identidades da educaçáo ambiental brasileira. Brasília: Ministério do Meio Ambiente. Diretoria de Educação Ambiental, 2004. p. 65-84.

LOUREIRO, C. F. B. Pesquisa-acáo participante e educação ambiental: uma abordagem dialética e emancipatória. In: TOZONI-REIS, M. F. C. (Org.). A pesquisa-açáo-participativa em educação ambiental: reflexóes teóricas, São Paulo: Annablume, 2007. p.13-56.

LOUREIRO, C. F. B.; COSSÍO, M. F. B. Um olhar sobre a educação ambiental nas escolas: consideraçóes iniciais sobre os resultados do projeto "O que fazem as escolas que dizem que fazem educação ambiental?" In: MELLO, S. S.; TRAJBER, R. (Org.). Vamos cuidar do Brasil: conceitos e práticas em educaçáo ambiental na escola. Brasília: Ministério da Educação, Coordenação Geral de Educação Ambiental. Ministério do Meio Ambiente, Departamento de Educação Ambiental: UNESCO, 2007. p. 58-63.

LOUREIRO, C. F. B.; TREIN, E.; TOZONI-REIS, M. F. C.; NOVICKI, V. Contribuiçôes da teoria marxista para a educação ambiental crítica. Cadernos Cedes, Campinas, v. 29, n. 77, p. 81-97, jan./abr. 2009. Disponível em https:// www.scielo.br/scielo.php?pid=S0101-32622009000100006\&script $=$ sci_ abstract\&tlng=es . Acesso em: 29 ago. 2019.

LOUREIRO, C. F. B. Sustentabilidade e educaçáo: um olhar da ecologia política. 1. ed. São Paulo: Cortez, 2013.

MORIN, E. O método 1: A Natureza da Natureza. 3. ed. Porto Alegre: Sulina, 2013.

MOTA, J. C.; KITZMANN, D. I. S. Um Estado da Questão sobre Ambientalização Curricular na Educaçáo Superior brasileira: práticas, desafios e potencialidades. Revista Eletrônica do Mestrado em Educaçáo Ambiental, Rio Grande, v. 34, n. 3, p. 72-92, set./dez. 2017. Disponível em: https://periodicos.furg.br/remea/ article/view/7475. Acesso em: 29 ago. 2019. 
SEPULCRI, B. N.; TRISTÃO, M. F. Formação continuada, pesquisa e narrativas em educação ambiental. Revista Eletrônica do Mestrado em Educaçáo Ambiental, Rio Grande, v. 34, n. 2, p. 190-203, maio./ago. 2017. Disponível em: https://periodicos.furg.br/remea/article/view/7036. Acesso em: 29 ago. 2019.

SILVA, N. N. E. S.; PEREIRA, J. L. G. A. Educação Ambiental e o Planejamento Educacional no Ensino Superior: a formação do professor. Revista de Educomunicaçáo Ambiental, v. 5, n. 2, p. 57-75, jul./dez. 2015. Disponível em: http://www.latec.ufrj.br/revistas/index.php?journal=eduambiental\&page=ar ticle\&op=view\&path\%5B\%5D=757. Acesso em: 29 ago. 2019.

SOUZA, V. M. Para o mercado ou para a cidadania? A educação ambiental nas instituições públicas de ensino superior no Brasil. Revista Brasileira de Educaçáo, v. 21 n. 64, p. 121-142, jan./mar. 2016. Disponível em: http://www. scielo.br/pdf/rbedu/v21n64/1413-2478-rbedu-21-64-0121.pdf. Acesso em: 29 ago. 2019.

TRAJBER, R.; MENDONÇA, P. R. (Org.). Educaçáo na diversidade: o que fazem as escolas que dizem que fazem educaçáo ambiental. Brasília: Secretaria de Educação Continuada, Alfabetização e Diversidade, UNESCO, 2007.

TORALES, M. A. A inserção da educação ambiental nos currículos escolares e o papel dos professores: da ação escolar à ação educativo-comunitária como compromisso político-pedagógico. Revista Eletrônica do Mestrado em Educação Ambiental, Rio Grande/RS, v. especial, p. 1-17, mar. 2013. Disponível em: http:// www.seer.furg.br/remea/ article/viewFile/3437/2064. Acesso em: 21 set. 2019.

TRISTÃO, M. A educaçáo ambiental na formaçáo de professores: redes de saberes. São Paulo: Annablume, 2004.

VIANA, P. A. M. O.; OLIVEIRA, J. E. A inclusão do tema meio ambiente nos currículos escolares. Revista Eletrônica do Mestrado em Educaçáo Ambiental, Rio Grande/RS, v.16, p. 1-17, 2006. Disponível em: https://periodicos.furg.br/ remea/article/view/2777. Acesso em: 29 ago. 2019.

VIEIRAS, R. R.; TRISTÁO, M. A educação ambiental no cotidiano escolar: problematizando os espaçostempos de formação como processos de criação. Educaçáo, Santa Maria, v. 41, n. 1, p. 159-170, 2016. Disponível em: https:// periodicos.ufsm.br/index.php/reveducacao/article/view/16129. Acesso em: 29 ago. 2019. 